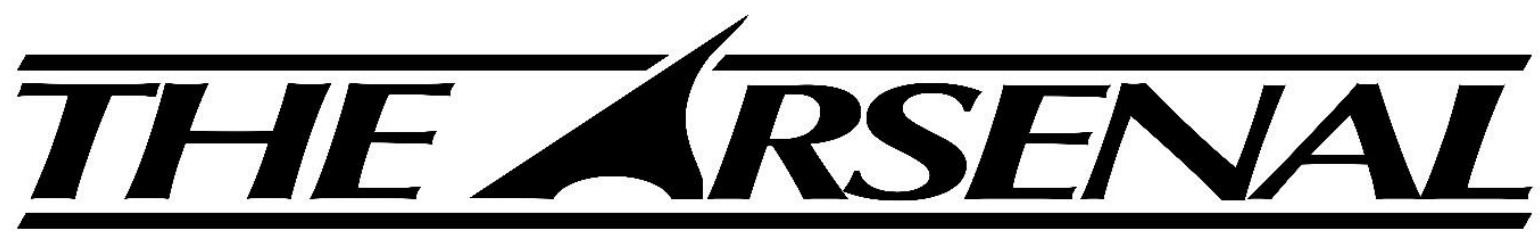

Augusta University's Undergraduate Research Journal

ISSN 2380-5064 | The Arsenal is published by the Augusta University Libraries | http://guides.augusta.edu/arsenal

Volume 4, Issue 1 (2021)

Special Edition Issue

\begin{abstract}
ATTENUATION OF RHO KINASE ACTIVITY AND PROINFLAMMATORY CYTOKINE RELEASE BY NIACIN IN PARKINSON'S DISEASE
\end{abstract}

Sneha Chauhan, Banabihari Giri, Marissa Seamon, Sharad Purohit, and Chandramohan Wakade

\title{
Citation
}

Chauhan, S., Giri, B., Seamon, M., Purohit, S., \& Wakade, C. (2021). Attenuation of rho kinase activity and pro-inflammatory cytokine release by niacin in Parkinson's disease.

The Arsenal: The Undergraduate Research Journal of Augusta University, 4(1), 7.

http://doi.org/10.21633/issn.2380.5064/s.2021.04.01.07

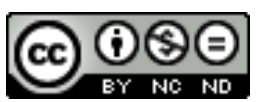

(C) Chauhan et al. 2021. This open access article is distributed under a Creative Commons Attribution NonCommercial-NoDerivs 2.0 Generic License (https://creativecommons.org/licenses/by-nc-nd/2.0/). 


\section{Attenuation of Rho Kinase Activity and Pro-Inflammatory Cytokine Release by Niacin in Parkinson's Disease}

Presenter(s): Sneha Chauhan

Author(s): Sneha Chauhan ${ }^{1,2,3}$, Banabihari Giri ${ }^{1,2,3}$, Marissa Seamon ${ }^{2,3,4}$, Sharad Purohit ${ }^{1,2,3}$, and Chandramohan Wakade ${ }^{1,2,3,4}$

Faculty Sponsor(s): Sharad Purohit, $\mathrm{PhD}$ and Chandramohan Wakade, $\mathrm{PhD}$

Affiliation(s): ${ }^{1}$ Department of Physical Therapy, ${ }^{2}$ Charlie Norwood VA Medical Center, ${ }^{3}$ Center for Biotechnology and Genomic Medicine, ${ }^{4}$ Department of Neuroscience (Augusta Univ.)

Funding: Augusta University CURS Student Research Grant

\section{ABSTRACT}

Parkinson's Disease (PD) is associated with the aggregation of $\alpha$-synuclein protein, which is the primary component of Lewy bodies found in brains of PD patients. Clinical trials have shown promising results with niacin (vitamin B3) supplementation for PD patients, encouraging further analysis of niacin's anti-inflammatory effects. In the central nervous system, microglia represent the first line of immune defense and exert an important role in producing cytokines (both pro- and anti-inflammatory). We utilized a human microglial cell line, HMC3 cells, to study the release of pro-inflammatory cytokines IL-6, IL-1 $\beta$, and IFN- $\gamma$ in response to $\alpha$-synuclein oligomers. Our studies show that niacin treatment results in a decrease of pro-inflammatory cytokines that are upregulated in the presence of $\alpha$ synuclein. In vivo studies demonstrate the association of Rho kinase (ROCK) with enhanced release of pro-inflammatory cytokines. Thus, the activation of ROCK pathway may be instrumental in microglial activation in the inflammatory response. Our preliminary studies show a decrease in ROCK activation with the addition of niacin to $\alpha$ synuclein oligomer-induced microglia. These in vitro experiments elucidate part of the underlying biological changes that may lead to significantly improved motor function for PD patients taking daily niacin. 